\title{
A Study of a CCD Camera for Vibration Measurement
}

\author{
Zulkifli Amin*, Muhammad Ikhsan \\ Universitas Andalas, Mechanical Engineering Department, Padang, Indonesia
}

\begin{abstract}
Vibration may occur in rotating equipment, for example on the transmission shaft of the gear. If the motor rotation is high enough, the load and torque could also be large enough. So that it can cause the shaft to vibrate and this vibration can damage the shaft. Therefore, the magnitude of vibration of the shaft need to be measured in order to monitor that the magnitude of the vibration is not high enough to damage the shaft. Usually for measuring the magnitude of this vibration is used a vibration meter. The weakness of the vibration meter is that the method of the measurement is by touching the measured object. So this measuring instrument is easily damaged by the vibration. An alternative to measure the vibration of a shaft is by applying an image processing method. Image processing is a method that performs processing of images digitally. The measurement of vibration by image processing method is tested on a vibrating shaft. The image of the vibrating shaft is captured by a CCD camera and then processed by a Matlab program to extract the value of vibration amplitude. From the tests performed, the measurement of vibration using the image processing method, the measurement can be done without touching the vibrating shaft. The obtained values of amplitude are deviate about $5.73 \%$ in average from the theoretical values. This method and tools can be used to measure the rotating shaft vibration amplitude provided the measurement instrument is calibrated prior being used by considering the value of deviation.
\end{abstract}

\section{Introduction}

Vibrations can occur in many components of machines for example on the transmission shaft gears. On the transmission shaft gears are mutually tangent for transmitting torque. This torque gives the load on the shaft radially. This load can cause the occurrence of deflection on transmission shaft rod. The deflection on the shaft causes the shaft not straight. This straightness deficiency causes the shaft to vibrate [1].

Rotating equipment produce vibration as a function of the dynamics of the machine such as un-straightness, misalignment and unbalance of the rotating parts. Measuring the amplitude of the vibration at certain frequencies can provide valuable information about straightness, alignment and balance of shafts, the bearing or gear condition, and the effects of the machine due to resonance from other structures Vibration caused by the rotating equipment such as motor, pump, and fan indicating the condition of the equipment. So, by conducting vibration analysis to check the characteristics of the vibrations, the condition of the equipment can be known [2].

Vibration measuring instrument commonly used is a vibration meter. This vibration meters are usually small and light. So, it is easy to carry. It generally consists of a probe and indicator to show the magnitude of the vibration. Vibration meter only gives information about the frequency of the vibration. This tool is generally used to determine mechanical condition and operation of an equipment. The weakness of the vibration meter is that the measurements is done only on a few specific points and the object to be measured need to be touched [3]. However, most machines in the industry, the vibration measurement point is located in a dangerous area. Sometimes, the vibration measurement point is difficult to reach when the machine is operating [4]. Therefore, to ease the vibration measurement and reduce the errors, it is proposed another method of vibration measurement. The method of vibration measurement by means of digital image capture on the objects, then the digital image is processed to be a numerical data which is used as the analysis vibration data. This method is usually called Digital Image Processing. A method of digital image processing is a method used to process or manipulate digital images which are stored in a twodimensional scale [5].

The main components of the Machine Vision system consist of hardware and software. The hardware that will be used in machine vision are a camera and a computer. The camera is an optical tool that is used to record images captured by a sensor mounted on the camera. The camera will be in use is a digital type camera. A digital camera is a tool for creating images of objects for subsequent bias through the lens of CCD sensors and lately on BSI-CMOS sensors (Back Side Illuminated) more efficient power sensors for more sophisticated cameras whose results are then recorded in digital format to in digital save media [6]. An example

\footnotetext{
*Corresponding author: zulkifliamin@ft.unand.ac.id
} 
of a software of a machine vision is Matlab. Matlab (Matrix Laboratory) is a program for numerical analysis and computation and is an advanced mathematical programming language formed on the premise of using matrix properties and forms. Matlab is a commercial product of the company Mathworks, Inc. which is developed using $\mathrm{C}++$ and assembler languages [7].

\section{Measurement Methods}

This research was conducted to collect vibration data on the shaft that occurs by measuring the vibration indirectly with the camera aids. The camera is placed in front of the shaft with a distance of $30 \mathrm{~cm}$. the camera will capture the pivot image directly on every second. The result will be processed later by Matlab. In the process there are three processes: Image Enhancement, image segmentation and image analysis. The purpose of the three processes is to determine the displacement position that occurs on the shaft when vibrating. The result of this process will be calculated by Matlab. The result of this calculation is the amplitude of vibration. The flow diagram of the measurement method can be seen in Figure 4.

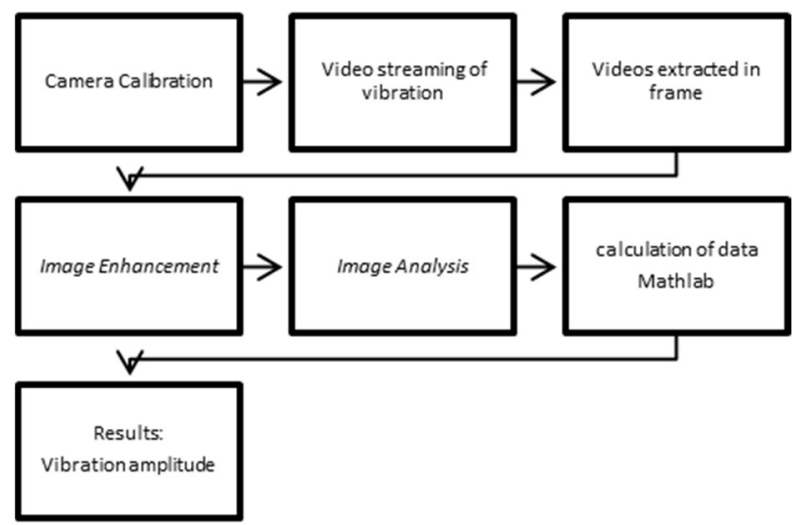

Fig. 4. Flowchart of the measurement method

As a constraint in designing a vibration measurement system on a cantilevered shaft with image processing method, the design specification is determined. The design of this test consists of two parts: vibration measuring instrument using image processing and model tested. The measurement test model can be seen in Figure 5.



Fig. 5.: Measurement test model
The vibration measuring device using image processing consists of a camera connected to a computer. The camera acts as a sensor of measurement and the computer as a transducer and a pointer or recorder during the measurement process. The model tested consisted of a shaft connected to a driving motor and loaded in the center of the shaft. The motor not only causes the axle to spin but also causes unwanted vibration effects. This vibration will be measured by a vibration measuring device using Image Processing.

\section{Results and Discussion}

The test results from three experiments of measuring the amplitude of vibration using the CCD camera are shown in Table 1. From data in the Table 1, there is a $5.73 \%$ difference between the results of the measurements made with this method of image processing compare to those of theoretical measurements. Although there is a difference of value of measurement, this still prove that the CCD camera can be used to measure the amplitude of vibration without touching the shaft. The accuracy of this vibration instrument can be improved by performing correlation and calibration to the $\mathrm{CCD}$ camera prior being used.

Table 1. Test results from three experiments of measuring the amplitude of vibration

\begin{tabular}{|c|c|c|c|}
\hline $\mathbf{n}^{\text {th }}$ & $\begin{array}{l}\text { Measured } \\
\text { amplitude } \\
(\mathrm{cm})\end{array}$ & $\begin{array}{c}\text { Theoretical } \\
\text { amplitude } \\
\text { (cm) }\end{array}$ & $\begin{array}{l}\text { Error } \\
\text { (cm) }\end{array}$ \\
\hline 1 & 0.117 & 0.376 & 0.178 \\
\hline 2 & 0.343 & 0.376 & 0.339 \\
\hline 3 & 0.361 & 0.376 & 0.359 \\
\hline \multirow{2}{*}{\multicolumn{3}{|c|}{$\frac{(\Sigma \mathrm{e})}{\left(\Sigma \mathrm{e}^{2}\right)}$}} & 0.876 \\
\hline & & & 0.276 \\
\hline & & & 0.292 \\
\hline
\end{tabular}

The standard error (SE):

Where: $=$ average error of the $n$-th experiment $n=$ number of data

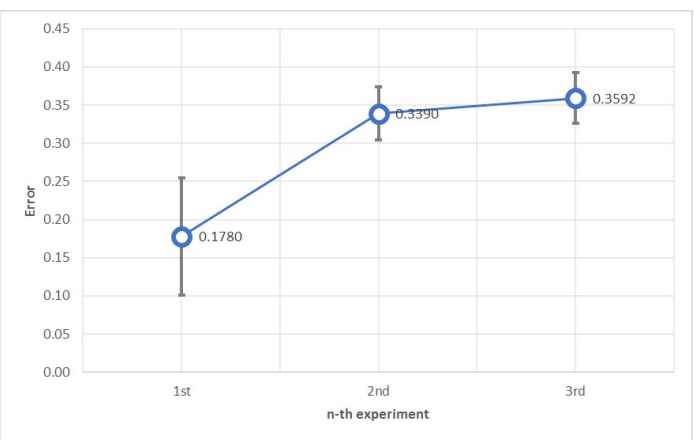

Fig. 6. Graph of vibration amplitude error from three experiments

The difference between the results of the measurements made with this method of image processing compare to those of theoretical measurements is due to lighting testing conditions that 
cause the camera difficult to focus on determining the light intensity released by the test model. In addition, the difference on test results is also due to that the speed of camera is not fast enough to capture the image frame. During period of measuring, the camera can only capture the shaft frame with a speed of 87 fps (frame per second) which is less fast. Speed of frame capture and lighting is very influential on program mapping. Mapping is done to determine the position coordinate of the vibrating shaft during frames capturing. In Figure 7 to Figure 9, it can be seen the script of the computer program as measurements software, image of the vibrating shaft captured by the CCD camera during measurements and the graph presenting the vibration measurements result respectively.

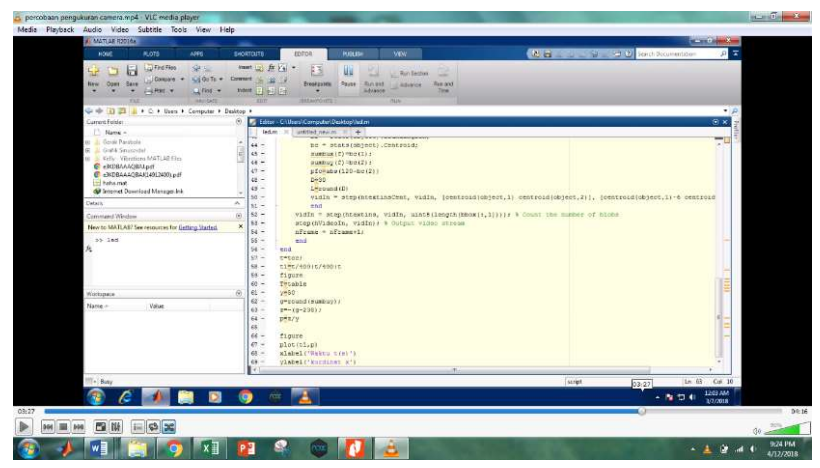

Fig. 7. Script of the computer program for taking measurements.

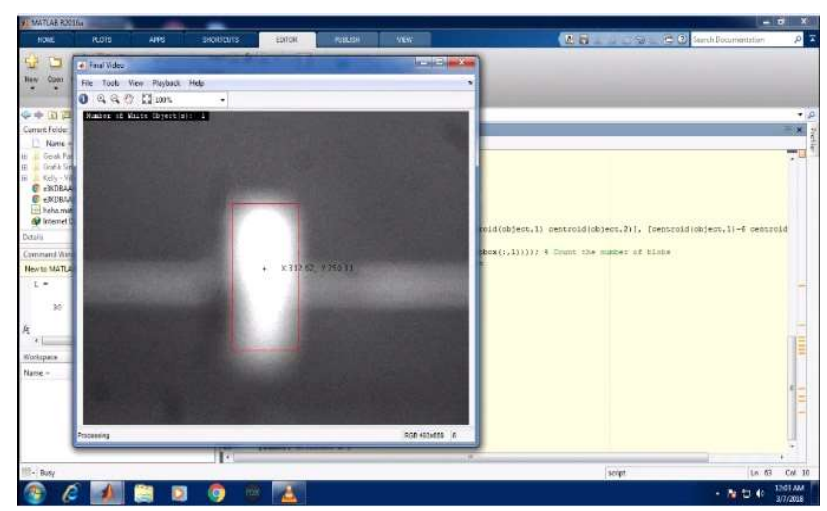

Fig. 8. Image of the vibrating shaft captured by the CCD camera during measurements.

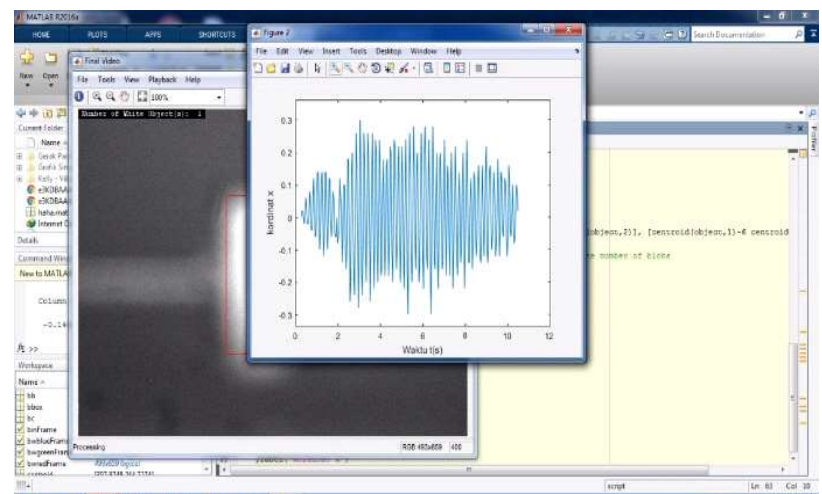

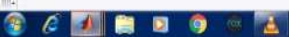

Fig. 9. Graph presenting the vibration measurements result.
This result shows that the average vibration amplitude that occurs for 10 seconds at the time of the test is $0.117 \mathrm{~cm}$. The following graph of the test results can be seen in Figure 10.

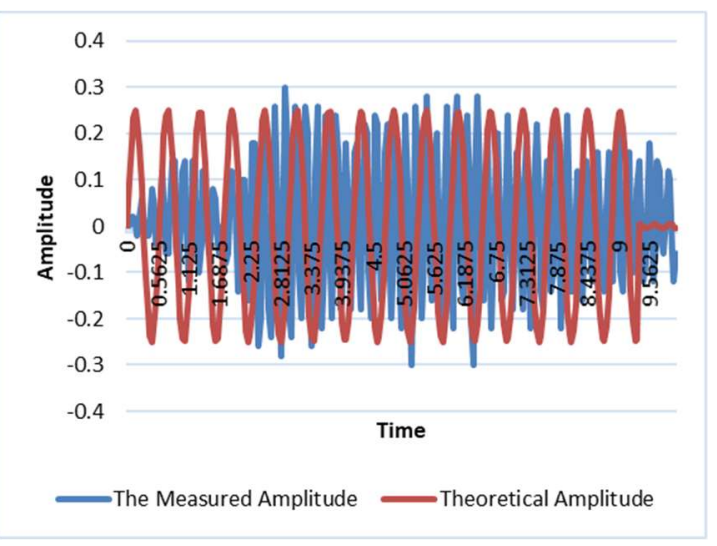

Fig. 10. Graph of measured and theoretical vibration amplitude

\section{Conclusions and Recommendations}

The conclusion of this research is (1) combining a CCD camera and an image processing method can be used to measure the amplitude of vibration without touching the vibrating component provided correlation and calibration have been done to the CCD camera prior being used. (2) the result of measurement of vibration measurement using image processing method shows the difference of measurement result of $5.73 \%$ from value of theoretical value. (3) the cause of the difference in the results of vibration with the method of image processing is due to the speed of camera frame capture and lighting intensity in the room.

The suggestion for this research is (1) to produce more precise measurements it is recommended to use a camera that has higher speed and resolution. (2) in the next research, the light intensity of the room should be properly adjusted so that the measurement more accurate.

\section{References}

1. Crowford, A. R. The Simplified Handbook of Vibration Analysis. Knoxville: SCI. (1992)

2. Harris Cyrill M., P. A. eds. Harris' Shock and Vibration Handbook. New York: McGraw Hill. (2002)

3. Mahmood, S. T. (kein Datum). Use of Vibrations Analysis Technique in Condition Based Maintenance. Stockholm: Royal Institute of Management.

4. Pain, H. J. The Physics of Vibrations and Waves. London: John Wiley (2000).

5. Rafael C Gonzalez, R. E. Digital Image Processing. Pearson Prentice Hall. (2013).

6. S Setiawan, A. A. Pengantar Pengolahan Citra. Jakarta: PT Elex Media Komputindo. (1992).

7. Vierck, R. K. Analisis Getaran. Bandung: Eresco. (1995). 